\title{
ESTRUTURA DE UMA AULA TEÓRICA II: FORMA
}

\author{
STRUCTURE OF A LECTURE II: FORM
}

Sandro Scarpelini ${ }^{1}$, Antonio Pazin Filho²

\begin{abstract}
Docentes. 'Departamento de Cirurgia e Anatomia. ${ }^{2}$ Departamento de Clínica Médica. Faculdade de Medicina de Ribeirão Preto - USP. Correspondência: Sandro Scarpelini. Rua Bernardino de Campos, 1000, $2^{\circ}$ Andar, CEES - 14015-030 Ribeirão Preto - SP sandro@fmrp.usp.br
\end{abstract}

Scarpelini S, Pazin Filho A. Estrutura de uma aula teórica II: forma. Medicina (Ribeirão Preto) 2007; 40 (1): 28-31.

RESUMO: Embora a formatação de uma aula seja passível de uma grande variabilidade, o conceito de começo-meio-fim deve sempre ser respeitado. A elaboração adequada, respeitando uma sequência lógica, com apresentação de tópicos com argumentações precisas e concisas, é um primeiro e largo passo para uma aula bem sucedida. Neste capítulo, procuramos abordar e sugerir aspectos de forma de uma apresentação, para garantir a fluência e a precisão na transmissão das informações.

Descritores: Aula Teórica; forma; elaboração. Didática. Educação Médica.

"O único lugar onde o sucesso vem antes do trabalho é no dicionário."

Albert Einstein

\section{1- INTRODUÇÃO}

Como já foi apresentada anteriormente, a fluência na apresentação de uma aula teórica pode ter impacto decisivo no sucesso da apresentação. A estrutura de uma apresentação com começo-meio-fim deve ser persistentemente perseguida pelo apresentador, desde os primeiros estudos para concepção da aula. A coerência na apresentação dos objetivos e, posteriormente, na apresentação e transição entre os diversos tópicos e suas respectivas evidências, assume caráter fundamental nesta desejada fluência. Embora este assunto tenha um grande viés de subjetividade e mesmo de aspectos culturais, acreditamos que seja possível se estabelecer critérios básicos para o desenvolvimento de uma apresentação formal. Neste capítulo pretendemos apresentar sugestões de como formatar a apresentação de uma aula teórica, respeitando estes critérios.

\section{2- ASPECTOS GERAIS}

De modo geral podemos traçar um paralelo entre uma aula teórica formal e um texto de pesquisa. O alvo final dos dois processos é "convencer" um determinado público da necessidade desta informação, da acurácia dos dados e da metodologia e a consistência da conclusão. Um bom texto de pesquisa necessita de: título, resumo, introdução, objetivos, metodologia, resultados, discussão e conclusão. Uma boa aula teórica deve apresentar: título, objetivos, introdução, conteúdo principal, conclusão e resumo. O conteúdo principal deve ser dividido em tópicos acom- 
panhados de suas evidências, os quais deverão ser apresentados sequencialmente até culminarem na conclusão. A dimensão da aula, ou o volume de informações que se pretende apresentar deverá ser adequado ao público alvo e proporcional ao tempo disponível para a apresentação, levando-se em conta as informações apresentadas no capítulo "Conteúdo".

O tempo da aula deve ser uma preocupação especial do apresentador. Frequientemente os convites para apresentações em congressos, simpósios e encontros são acompanhados de um tempo limitado, como 20 ou 30 minutos. Habitualmente, as apresentações de temas livres são limitadas a 10 minutos, sem direito a qualquer tempo excedente. Por outro lado, já foi discutido a dificuldade de retenção de informação pela platéia em aulas com mais de 45 a 60 minutos de duração. Desta forma, o respeito ao tempo disponível e a adequação do conteúdo a este tempo, deve ser uma preocupação fundamental do apresentador. A prática contínua, a distribuição adequada do tempo pela importância dos objetivos e o treinamento prévio cronometrado da aula são métodos válidos para se obter a precisão necessária para a apresentação.

O controle do tempo é uma atividade complexa que depende da estruturação interna do conteúdo e das condições em que é realizada a apresentação. A forma da aula é um recurso que pode auxiliar no controle do tempo. Ao conhecer a estrutura do que será apresentado, a forma da aula passa a ser um instrumento de localização temporal para o apresentador. Se este sabe que existem cerca de 30 diapositivos e está apresentando o décimo, pode olhar discretamente no relógio e ter uma idéia se deverá adiantar ou retardar o andamento da aula. Terá uma idéia se pode se extender em perguntas ou se deve limitá-las para cumprir seu objetivo.

Embora existam diversos formatos para elaboração de uma aula, optar-se por formatos mais clássicos, principalmente quando se está começando a desenvolver as atividades didáticas, pode ser um bom recurso. Isto permite ao palestrante um fator a menos de preocupação e confere um senso de segurança para a platéia, que está habituada com este formato pela exposição prévia a outras aulas. Ambas as situações são exemplos de como o adulto se sente mais confortável em terreno conhecido.

A seguir apresentaremos, detalhadamente, as sugestões para forma de cada item que compõe uma aula teórica tradicional.

\section{1- O Título}

A apresentação inicial da aula é muito importante. A escolha de um título curto e objetivo que deixe claro o principal conceito que se pretende transmitir é fundamental. Títulos extensos e muito descritivos devem ser evitados, com excessão daqueles que fazem parte de um trabalho especifico, como na apresentação de uma dissertação. Acompanhando o título é conveniente se incluir o nome e titulação do apresentador, bem como a instituição a que pertence ou esta representando. Lembre-se que cada aula, apresentação em congresso ou outro evento é uma nova oportunidade para divulgação pessoal e institucional, e que deve ser reforçada com a apresentação dos nomes e emblemas institucionais. Como exposto anteriormente no capítulo de "Aprendizado para Adultos", esta apresentação no entanto, deve ser principalmente motivada para convencer o expectador do porque prestar atenção ao que este palestrante em específico está dizendo. Muitas vezes, isto é muito reforçado pela instituição que o palestrante representa.

\subsection{Os Objetivos}

A explicitação dos objetivos é uma prática aconselhável. A descrição concisa de como se pretende discorrer sobre o tema cria uma expectativa positiva na platéia, e expõe claramente a importância da aula. Deixa transparente, também, os pontos que o apresentador considera mais significativos, e como ele pretende avaliar a retenção do conhecimento por parte da platéia. Habitualmente os objetivos devem ser construídos com verbos relacionados a algum tipo de habilidade a ser adquirida pela platéia, utilizados na sua forma infinitiva, como por exemplo: "descrever as principais regiões anatômicas", "realizar a imobilização da extremidade", ou ainda "discutir as principais formas de apresentação". Lembre-se que os objetivos a serem atingidos não devem ultrapassar cinco ou seis itens, o que já permite normalmente a elaboração de uma apresentação completa. Finalmente, os objetivos estão sempre intimamente relacionados com a conclusão final da aula, como se esta última fosse uma resposta e um reforço aos objetivos traçados inicialmente.

Os objetivos não necessitam ser explicitados, mas devem estar presentes na mente do palestrante e devem ficar claro para a platéia. Concretizá-los na forma de um diapositivo é um recurso útil tanto para a 
platéia como para o palestrante. Também é uma excelente forma de documentação da atividade para posterior revisão.

\section{3- A Introdução}

Como em todo o texto científico, a introdução constitui um dos principais momentos para se atrair a atenção do público para o assunto a ser discutido. Neste instante, pretende-se situar a platéia com relação à importância do assunto e o "estado da arte", trazendo o conhecimento acumulado por outros pesquisadores, instituições e academias. Contudo, lembre-se que uma aula nem sempre é uma tese e, portanto, não se deve levar este momento à exaustão do conhecimento, com o risco de perder o foco do conteúdo principal e, principalmente, consumir inadequadamente o seu valiosíssimo tempo. O conteúdo a ser explorado na introdução depende do tema principal da aula. Por exemplo, ao se discutir o tratamento da insuficiência cardíaca, provavelmente será necessário uma revisão das principais etiologias e fisiopatologia desta condição, ou ainda para se discutir a técnica cirúrgica da apendicectomia será necessária uma revisão anatômica. Lembre-se sempre do foco principal da aula para determinar a dimensão e a profundidade da abordagem no conteúdo da introdução.

Todo este conhecimento deve ser exposto respeitando-se os princípios de Aprendizado do Adulto e Interação com a platéia apresentados neste Simpósio. Lembre-se que a motivação depende de uma concatenação com a atividade do expectador e, portanto, uma das técnicas naturais de se expor este conteúdo é relacionando-o com problemas que o expectador enfrenta em sua atividade diária. Resumir o exposto ao final e introduzir o conteúdo principal com uma pergunta também são técnicas válidas.

\section{4- O Conteúdo Principal}

Neste momento se inicia a aula propriamente dita. Os tópicos devem ser apresentados de maneira a permitir fluência por parte do apresentador, seguindo a sequência lógica do assunto e respeitando a ordem apresentada para os objetivos. Informações objetivas, dados numéricos e estatísticos são apresentados, seguidos de argumentações e exemplicações. Frequentemente, neste momento, a utilização de evidências científicas será útil para reforçar os conceitos, e garantir a confiabilidade das informações transmitidas. Como já foi dito anteriormente, as imagens podem colaborar na retenção de informações, portanto este pode ser o momento adequado para inserir figuras relacionadas ao tema, sejam elas pessoais ou de outros pesquisadores. Neste ponto, vale ressaltar a necessidade de se explicitar a origem dos dados, figuras, gráficos ou outros recursos que possam ser utilizados durante a apresentação. Uma citação deve sempre acompanhar este tipo de inserção, em primeiro lugar para se garantir os direitos autorais da fonte de consulta, e também para permitir que o expectador se dirija posteriormente ao trabalho original, completando seu estudo se assim o desejar. Também devemos zelar pela confidencialidade dos dados de pacientes, eliminando qualquer possível forma de identificação em fotos e figuras (i.e. eliminando nomes, registros de exames radiológicos ou outros, assim como evitando a apresentação da face de pessoas).

A informática revolucionou a obtenção de material audio-visual para a confecção de aulas formais. Contudo alguns cuidados devem ser tomados como a utilização de figuras, gráficos e tabelas em outras línguas. A opinião destes autores é de que, em sendo a apresentação direcionada para o público nacional ou em evento cuja língua oficial seja o português, todo o material seja preparado nesta língua. Portanto a adequação do material deverá ser realizada sempre que possível, respeitando a origem da fonte científica. Temos que ter sempre em mente que a aula se destina a um público específico e o preparo do material deve ser voltado para que este público compreenda o que está sendo dito. $\mathrm{O}$ adulto não consegue passar para o passo seguinte se não compreender algum ponto da informação.

Finalmente, reforçamos que o conteúdo principal provavelmente ocupará 70 a $80 \%$ do tempo disponível para a apresentação. Durante este tempo o apresentador deverá utilizar todos os recursos para garantir a maior retenção possível por parte da platéia, procurando evoluir continuamente para um fechamento conclusivo da aula.

\section{5- A Conclusão}

A conclusão da aula deve estar diretamente relacionada ao título escolhido e aos objetivos expostos inicialmente. Esta parte da aula deve ser concisa e objetiva, sendo restrita aos principais pontos apresentados. A conclusão não deve ser um resumo de tudo o que foi exposto, mas sim a visão final ou uma ponderação de tudo o que foi discutido. 


\section{6- O Resumo}

De maneira diferente do que se propõe para o resumo de um artigo científico, o resumo de uma aula pretende reforçar, para a platéia, a idéia de que os objetivos propostos foram adequadamente discutidos pelo apresentador. Mais uma vez se confirma os pontos cardinais deste assunto e aquilo que se pretende utilizar como avaliação da retenção do conteúdo da aula. Como nos objetivos, apenas alguns pontos (5 a 6), devem ser alçados para este tipo de reforço e deve haver uma concatenação entre o que está sendo resumido e o que se propôs a ser dito. Nunca deve ser exposto um objetivo que não seja cumprido até o final da atividade.

\section{3- CONSIDERAÇÕES FINAIS}

Certamente, a elaboração de uma aula formal é uma atividade complexa. Não se pretendeu aqui preparar uma "receita de bolo", já que o assunto não permite tal estratégia. O resultado final da elaboração de uma aula depende de múltiplos fatores, incluindo aspectos culturais, tempo de atuação e caráter pessoal do apresentador, assunto a ser abordado, dentre tantos outros. A espectativa principal é que estas sugestões, dentro do corpo deste Simpósio, completem uma orientação inicial para quem pretende exercer com êxito este aspecto da docência.

Scarpelini S, Pazin Filho A. Structure of a lecture II: form. Medicina (Ribeirão Preto) 2007; 40 (1): 28-31.

ABSTRACT: Although a formal lecture can be made with a great variability, the concept of beginning-middle-end structure should always be respected. The lecture should follow a logical sequence, with objectives topics and accurate argumentation, as a first and very important step to a successful presentation. In this chapter, we suggest some different aspects of the form of a presentation, to guarantee fluency and precision in the transmission of knowledge.

Keywords: Lecture; form; elaboration. Didactic. Education, Medical.

\section{REFERENCIAS CONSULTADAS}

1 - Advanced Trauma Life Support For Doctors - ATLS - Faculty Manual. 7th ed. Chicago, IL: American College of Surgeons, Committee on Trauma; 2004.

2 - Collins J, Mullan BF, Holbert JM. Evaluation of speakers at a national radiology continuing medical education course. Med Educ Online [serial online] 2002;7:17. Available from http:// www.med-ed-online.org.

3 - Gonçalves EL. Pedagogia e didática: relações e aplicações no ensino médico. Rev Bras Educ Méd 2001; 25(1): 20-6.

4 - Núcleo de Pesquisa e Extensão de Medicina - CCBS - UEPA. Manual do trabalho científico. 6 ed. Elet. Belém, PA: UEPA 2006.
5 - Pazin Filho A, Scarpelini S, Schmidt A. Análise qualitativa da elaboração e apresentação de aulas teóricas por alunos de pós-graduação da Faculdade de Medicina de Ribeirão Preto Universidade de São Paulo. Medicina (Ribeirão Preto) 2007; 40 (1): 51-62.

6 - Sullivan RL, Wircenski JL. Technical presentation workbook. New York: ASME Press; 1996.

Recebido em 07/11/2006

Aprovado em 13/03/2007 